\title{
Ecology: Creative Tool in Understanding Interrelated System
}

\author{
Diandra Pandu Saginatari ${ }^{1, *}$, and Paramita Atmodiwirjo ${ }^{1}$ \\ ${ }^{1}$ Department of Architecture, Universitas Indonesia, Indonesia
}

\begin{abstract}
Moving towards a world with higher environmental awareness, the concept of 'ecology' has become particularly relevant for current architectural discourses. Studies about ecology sometimes are directly translated to sustainability because of its focus on efficiency of material and energy process. This paper argues that understanding ecology requires an ability to reveal the intro/interrelationship within the complex yet flexible ecological system. Demonstrating how 'ecology' is incorporated in the first year of architectural education, this paper aims to explore how ecology could be the basis of in developing an analytical tool towards the grounded understanding particular issue of the ecological system and its role as input in creative processing architectural education. The result of this study suggests how ecology has the potential as an analytical tool for reading the interrelated system.
\end{abstract}

Keywords: ecology, design tool, creative process, interrelated system.

\section{Introduction}

There has been a significantly increasing concern on environmental issues in architecture. Architecture starts playing a role in 'correcting' ecological damage caused by the modern society that is shown through the tendency of architects to incorporate environmentally friendly strategies such as using local and energy efficient material, energy harnessing devices, and living component, such as green roof, in their designs (Sykes, 2010). Responses toward these issues are undoubtedly critical in architectural discourse since it also derives the direction of architectural education. It is presented through an inclusion of ecological discourse as the center of architectural education.

Ecology now becomes a common term in architectural education; terms such as ecology-based concept, performance ecology, and ecology and sustainability are increasingly used in architectural education (Goodbun, 2010). It apparently shows that ecology emerges as a complex discourse that closely relates to advanced practical and technical aspects of architecture that tends to be addressed at the later stage of the architectural education. However, this paper argues that the discourse of ecology is essential to be incorporate even in the early stage of architectural education. It does not suggest that we have to push the ecology in advanced practical and technical sectors to be studied in the first year. This paper believes that there is a way to transfer the knowledge of ecology through a creative process that is usually explored in early stage of architectural education.

One of the ways to transfer the knowledge of ecology through creative process is through an understanding of the ecology itself. This paper explores how the understanding of ecology that reveals the essential core of ecology which is the reading of interrelated systems could be a trigger for creative process. This creative process could become the medium in which ecology is explored, learned and understood by firstyear architecture students of the Department of Architecture Uiversitas Indonesia. This paper will use examples of student projects to show how the understanding of ecology could be incorporated in the creative learning process of the first year of architectural education.

\section{Ecology in Architectural Education}

In past decades, as a multifaceted discipline, the progress of architecture is determined by multiple themes that are emerged within the discipline such as the advancement of technology as new modes of design, environmental issue, everydayness and the phenomena of the "starchitect" (Sykes, 2010). The importance of the environmental issues and the emergence of ecology in the discourse revolves around the tendency of architecture to 'betrays nature' in its every process since the historical time (Ingersoll, 2012). And now, we could easily see the effects such as in the form of climate change. In response to overhaul the ecological damage, ecology becomes the core of architectural discourse.

Ecology is a branch of Biology dealing with the science of the relationship between the organism and its environment. Lately, as we are moving towards broader questions of environmental awareness, ecology emerges across disciplines and seems to signify a paradigm rather than a discipline (Goodbun, 2010). The use of 'ecology' as an additional term in specific disciplines refers to an additional perspective that somehow tries to reveal the way system works by seeing relation and interaction of

Corresponding author: diandrasaginatari@gmail.com 
parts within the system. Industrial Ecology, Urban Ecology, Urban Political Ecology, Social Ecology, Human Ecology and more are examples of the terms using ecology as a suffix, and it indeed indicates a discourse that focuses on revealing relation and interaction within the specific system. For example, industrial ecology, even though it is normative, tries to see how nature, as structure and function, works to be applied to existing industrial system that aims for efficiency; meanwhile Urban Political Ecology (UPE) tries to reveal nature-society relationship as dynamic and networked circulations that reorganize social and physical environments into socio-cultural assemblages (Newell and Cousins, 2014).

The use of 'ecology' as an additional term is also used in architecture and architectural education. Terms such as ecology-based concept, performance ecology, and ecology and sustainability are some of the currently used theme examples in architectural education, showing that architecture as a discipline, need to accentuate the inclusion of this topic in the education.

Catala (2010) stated that:

"Ecology is generally and perhaps too immediately linked to sustainability. The etymology of the word ecology (from the Greek Oikos, 'house' or 'living relations' and logia, 'study $\left.o f^{\prime}\right)$ however, does not necessarily imply the prioritisation of energy-efficient solutions, nor does it favour the notions of 'green' or of 'good' for that matter. Ecology refers to the interdependent (enduring or temporary) relationship between the physical and biological components of an environment that function as one whole ecological unit." (p.89)

Catala's statements are also reflected in architectural education. In architectural education, studies on ecology are translated to sustainability through a focus on efficiency of material and energy process. This focus generates phrases such as 'green architecture' or 'zero energy building'; with emphasis on quantitative methods within these studies. It directly relates to practical and technical aspects of architecture which include practical and technical complexity that will construct advanced skill and knowledge for the architecture student. It seems to indicate that knowledge of ecology will then imply to the implementation of technology to solve and reduce ecological damage. However, this paper believes that the knowledge of ecology in architecture is not merely a problem-solving tool through a practical and technical application that requires quantitative approach. Knowledge of ecology in architecture has the potential to be an analytical tool, as ecology comprises relation and interaction in the complexity of systemic nature such relation and interaction construct complexity which becomes the central idea in ecology.

\section{Ecology and Complexity}

"Ecological systems are complex assemblages of interacting organisms embedded in an abiotic environment" (Hartvigsen et all, 1998, p:427), then, ecology is about reading relation and interaction in complexity. It is undoubtedly true that ecological system consists of various parts or elements. Relation and interaction imply connectivity among parts or elements which together constructing the system. As illustrated in Figure 1, there is an issue about the relationship between parts and wholes that is central in ecology (Proctor and Larson, 2005). How parts construct wholes then generate complexity. Hartvigsen et all (1998) stated that complexity in ecology is emerged from the interspecific and intraspecific interaction among parts or elements, and this interaction exists in space and through time. We could conclude that we could see interaction in ecological system as events that exist specifically in particular context. This means that context plays a significant role in determining the event, and it happens through time which usually indicate the dynamic quality.

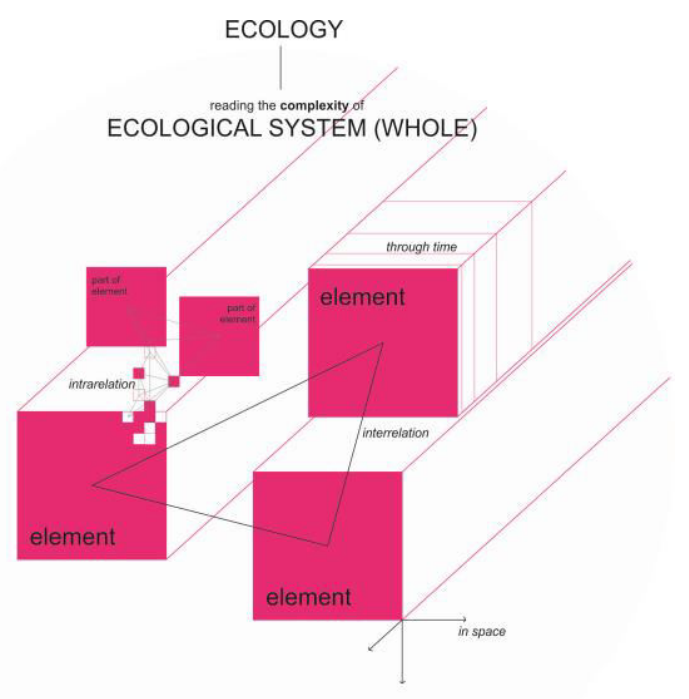

Fig. 1. Diagram of Ecological System.

The complexity in ecological system implies that ecology, which studies about an ecological system, is able to reveal complexity. Loehle (2004), in his paper titled Challenge of Ecological Complexity, suggests that complexity in ecology has at least six types: spatial, temporal, structural, process, behavioural, and geometric. In ecology, spatial complexity refers to vegetation patterns and species distributions. Spatial complexity will cause temporal complexity along with population dynamic and fluctuating climate and weather. Structural complexity deals with relationship and network within an ecosystem and relates to processing complexity that refers to the process which contains many steps or components. Furthermore, since ecology is a study about living organisms in its environment, behavioural complexity arises because of the behavioural response of the living environment to the environment. The living things and the environment also consist of distinct ecological objects that have geometric aspects which will influence an ecological system.

From Loehle's types of complexity in ecology, we could deduce how these complexities construct the 
ecological system that comprises relation and interaction among elements in space and time. Complexity such as spatial, structural, and geometrical could relate to space within which the system exists. Temporal complexity implies that time is an aspect that will always significantly influence as time causes temporality in the first place. Some complexities such as structural, process, behavioural seem to have a role in composing the relation and the interaction in the ecological system itself. Meanwhile some complexities such as geometrical and behavioural could also refer to the aspects that create the elements or objects.

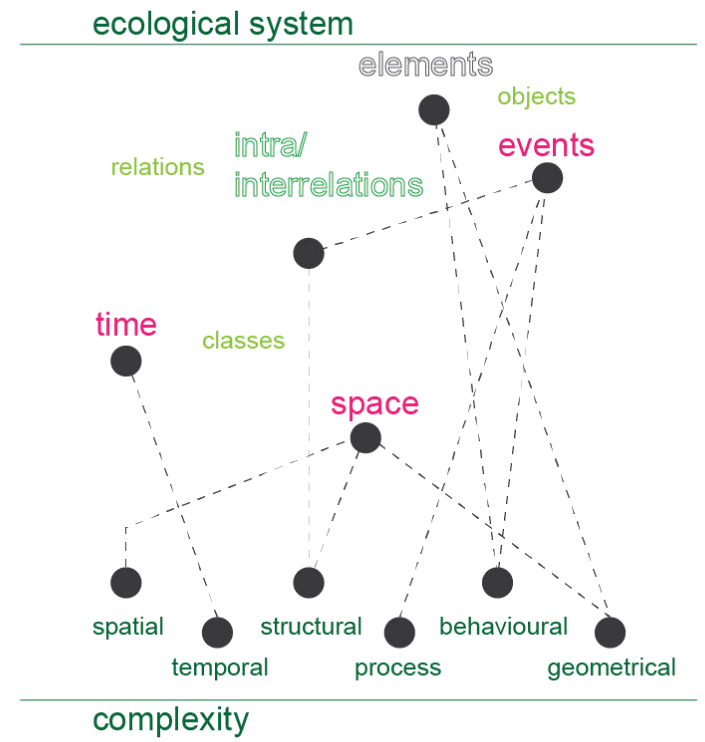

Fig. 2. The Complexity of Ecological System Diagram Based on Loehle (2004) and Hartvigsen et all (1998).

As shown in Figure 2, these types of complexity could be directly related to the essential nature or mechanism of the ecological system which, as stated above and based on Hartvigsen et all (1998), consist of relation and interaction among elements in space and time. To help to reveal the complex ecological system, Lohle (2004), suggests that we could break down the system into objects, classes, and relation. Objects refer to the elements of the system, while classes could refer to the organisational and hierarchical structure in the system, and relations could refer to the nature of the connectivity among elements that construct the system. This could structure our analysis toward an ecological system. By structuring the understanding of the complexity of ecological system we could generate an 'ecological' analytical tool that is substantially relevant in architecture.

\section{Ecology and Creativity}

As we unravel the nature and the complexity of an ecological system, we could strongly relate the vocabulary used in the discussion with the vocabulary that we use in architecture. The use of vocabulary such as spatial, temporal, geometrical, relation, interaction, and even the concept of space and time imply that somehow the ecological system is constructed as a structured spatial relationship. This 'ecological' analytical tool suited well with the analytical process in architecture, since in architecture we are expected to use structured analysis to analyze spatial settings or issues. This is what this paper suggests, ecology in architecture is not merely about a sustainable solution, but it could be used as an analytical tool that could be input at any level of an architectural design process.

The use of 'ecological' analytical tool in architectural education is one of the ways to embody ecological knowledge and understanding in architecture that could be implemented even in the first year of architectural education. This paper will illustrate several student projects in Basic Design Studio 1, in the first semester at the Department of Architecture Universitas Indonesia. It comprises basic design and communication knowledge and basic visual art that become the basic competencies for architecture students before they start their Architectural Design Studio in later semesters. This studio uses the triggers that are closely related to creative architectural practice, and one of which is the implementation of this 'ecological' analytical tool as trigger in a creative process.

Light and Shadow is the title of the final project in Basic Design Studio 1. In the final project, the students are challenged to develop their creative ideas in creating two and/or three-dimensional work based on sensitivity and critical thinking on light and shadow exist in various possible context through demonstration of creative exploration of media and techniques. This project offers 5 different units, one of which is titled The landscape of Light and Shadow. This particular unit offers the opportunity to explore the system and relationship between light and shadow particularly in a natural setting where Sun will be the main source of light. Students are encouraged to conduct visual and/or spatial experiments in a natural setting, that consists of various surfaces such as ground surface, water, vegetation, and even exterior of a building, to reveal the relationship of light and shadow as a dynamic spatial quality of the landscape itself. The term "landscape" in Landscape of Light and Shadow is not merely referring to the natural landscape. It refers to how light and shadow is being understood as a scape within which ecological relationship among the elements construct the system of light and shadow itself. 
landscape

of light and shadow

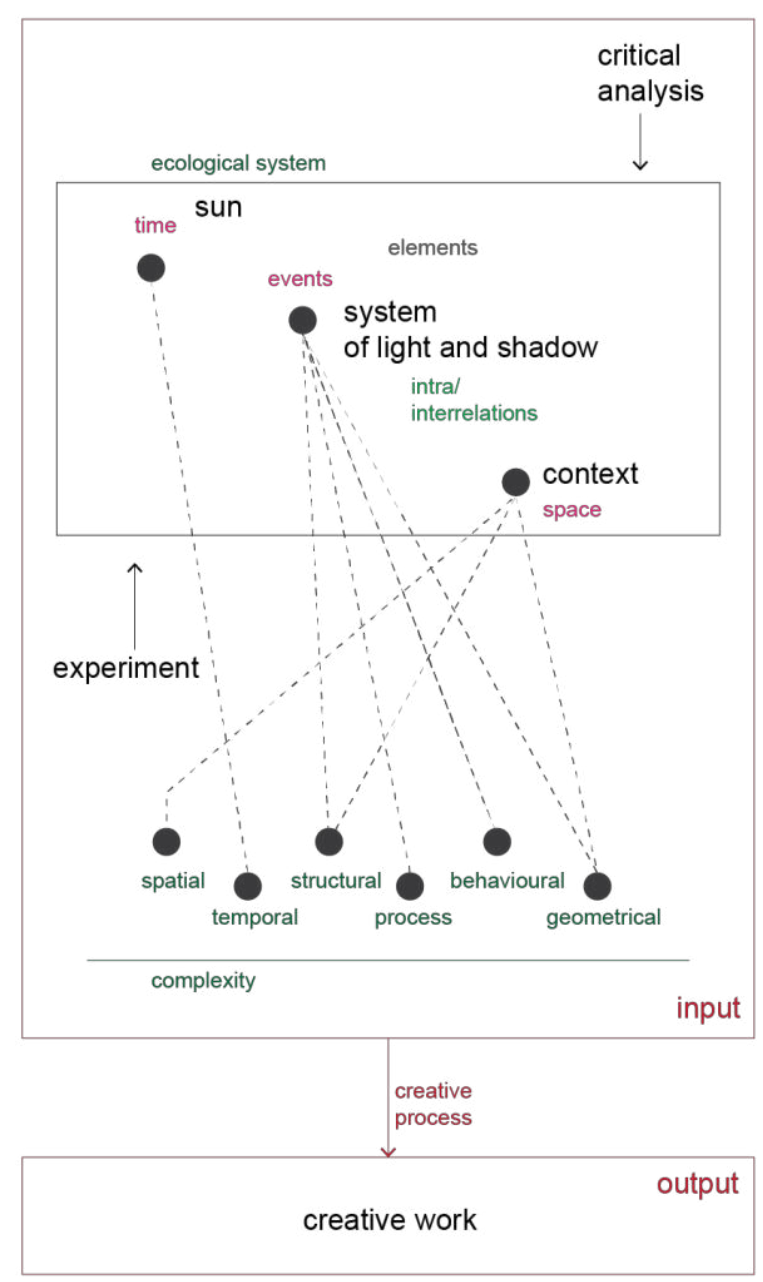

Fig. 3. Mapping the Brief of Landscape of Light and Shadow in the Complexity of Ecological System.

The short brief if the project becomes the trigger and basis for the students to develop their creative ideas. As shown in Figure 3, the brief itself has the potential to be an input of creative process that could implement an 'ecological' analytical tool. In the next part, this paper will discuss some of the students' works to unravel how the project demonstrates ecological analysis as input for a creative process. The unravelment of the demonstration is conducted by mapping the process of each project according to the vocabulary of complexity in the ecological system.

Project \#1: 2500 Shades of Shadow. This project explores the composition of umbra and penumbra of shadow. It began with research on how umbra and penumbra are formed in the shadow that leads to the understanding of umbra as the darker part of shadow and penumbra as the lighter part of the shadow. Then, an experiment was conducted to know the aspects that influence the degree of umbra and penumbra on the shadow. The experiment found that the height of the object from the surface of which the shadow existed affected the value of the colour of umbra and penumbra. The shorter the height, the object created the darker value of umbra and penumbra, and the value get lighter as the object get higher. Then, based on this experiment, further observation was conducted to collect umbra and penumbra from objects with different heights and different surfaces of which the shadows were formed.

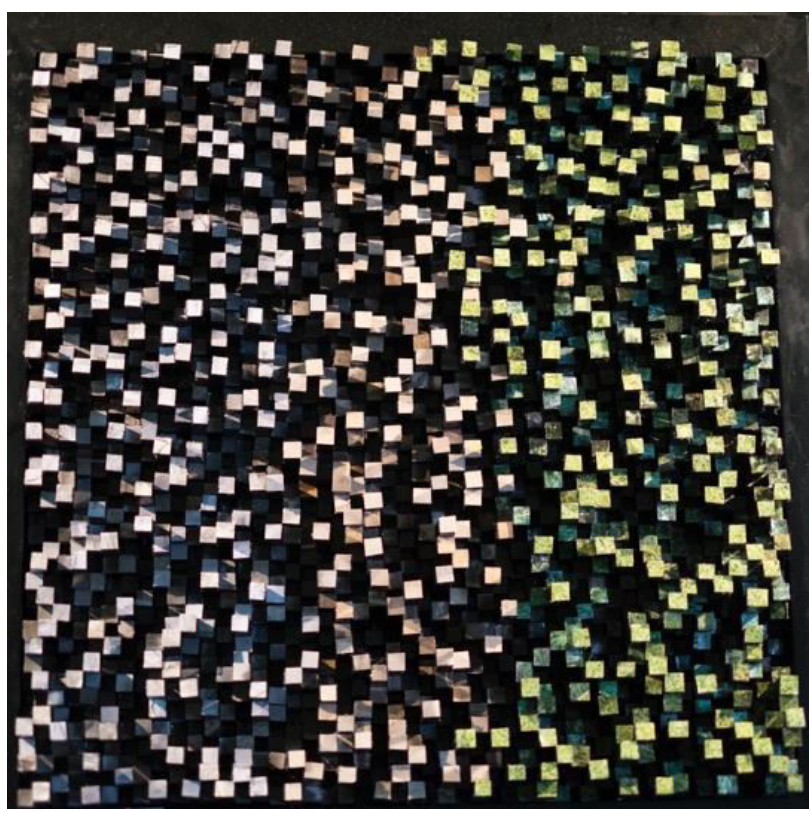

Fig. 4. 2500 Shades of Shadow by Adwani and Triarianti, 2016.

The output of this project is a catalogue of umbra and penumbra presented in a collage of $25001 \mathrm{~cm} \mathrm{x} 1 \mathrm{~cm}$ squares of shadows which are collected from photographs of umbra and penumbra in the observation. Each square of shadow has a different height from the surface. Referring to the findings, the higher the square, the lighter the value of the shadow shade. This work presents an artistic composition and the detailed data of umbra and penumbra that are based on ecological analysis that derives understanding about light and shadow, especially umbra and penumbra.

Project \#2: Kridaprana Andakara. The title is derived from Sanskrit Language meaning change of sunlight reflection on vertical surface. This project explores the shifting position of sunlight reflection. It began with the basic understanding of reflection that consisted of elements such as light source and flat reflective surface. As a system reflection happened when incident ray with a particular angle of incidence hit a flat reflective surface and created reflected ray with the same certain angle of reflection as the angle of incidence. So, one of the aspects that influenced the reflection was the angle of the ray. An experiment was then conducted to explore how the reflection of sunlight changed through time. By using several mirrors and vertical surface as a canvas for the reflection, the experiment captured that every 10 minutes, the reflection moved up or down around $2 \mathrm{~cm}$ depending on the position of the mirror. In the determined duration of time, the experiment produced a mapping of changing reflection of sunlight. 


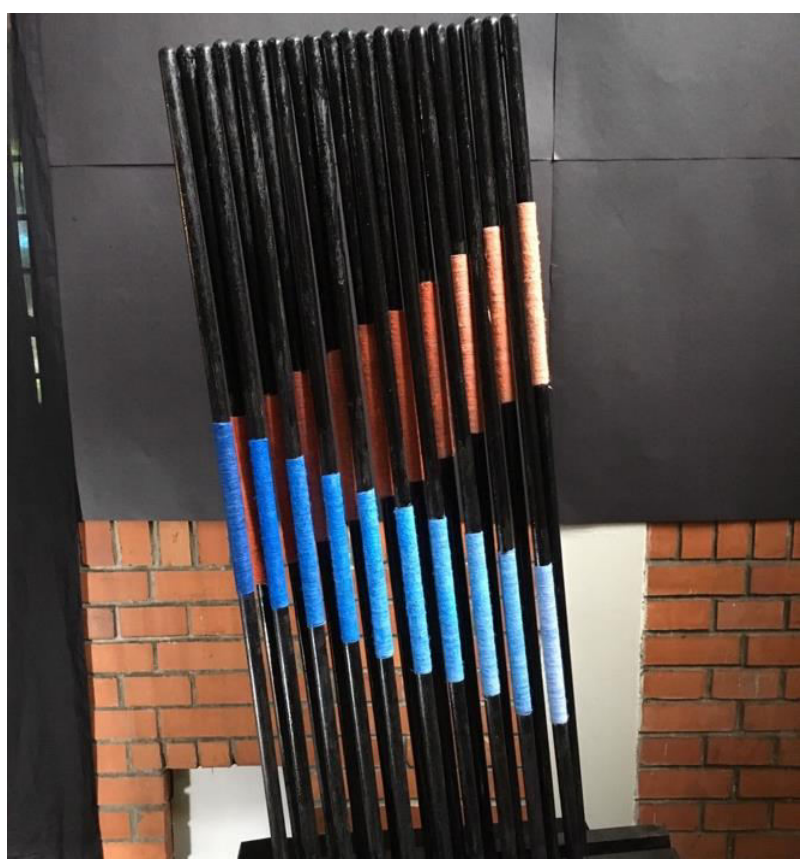

Fig. 5. Kridaprana Andakara by Agusiwi and Afifah, 2016.

The output of this project is a mapping of shifting reflection of sunlight presented as a three-dimensional work that consists of vertical surfaces with colour marks showing the changing position of sunlight reflection. Complementary colours of red and blue are used to signify the different direction of the shifting position of sunlight reflection. This work presents a creative map showing the dynamic flow of sunlight reflection based on an experiment that includes ecological analysis on the phenomena of reflection.

Project \#3: Distorsi Dalam Waktu (Distortion in Time). This project explores the changing shape of shadow from a man-made object through time. It began with a basic understanding of how the shadow of a manmade object in an outdoor setting was formed and changed through time. Then observation and experiment were conducted to explore how the shadow of man-made object in outdoor setting changed, both its position and its shape. The observation and experiment found that as the sun moved, the position and shape of the shadow changed. The shape of the shadow of the object get distorted as it changed because of the movement of the sun. The intensity of the sunlight also played a role in forming the shape of the shadow as the higher the intensity, the sharper the shape of the shadow that was created.

The output of this project is an abstraction of shapes of shadows presented in three-dimensional work that consists of horizontal layers of changing distorted shapes of shadow. Different distorted shapes of shadows are stacked layer by layer based on the timeline of the observation. The work is displayed on the ground, as of how the shadow of the object is, to help make sense the idea behind it. This work presents the findings of observation and experiment, which requires an ecological analysis on how sunlight could create ever changing shapes of shadow, which are creatively processed through abstraction being delivered as an artwork.

From the explanations above, each project has its specific understanding of light and shadow. Each of them is applying 'ecological' analysis in the process as we could always relate the development process with the essence of the ecological system and the complexity.

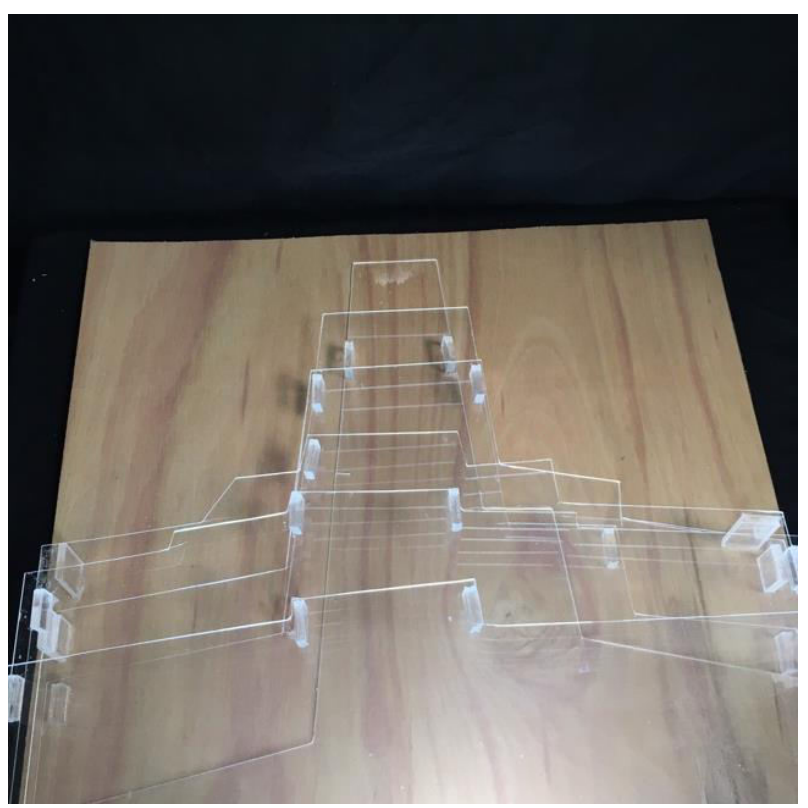

Fig. 6. Distorsi Dalam Waktu by Ratriananda and Kusumowidjojo, 2016.

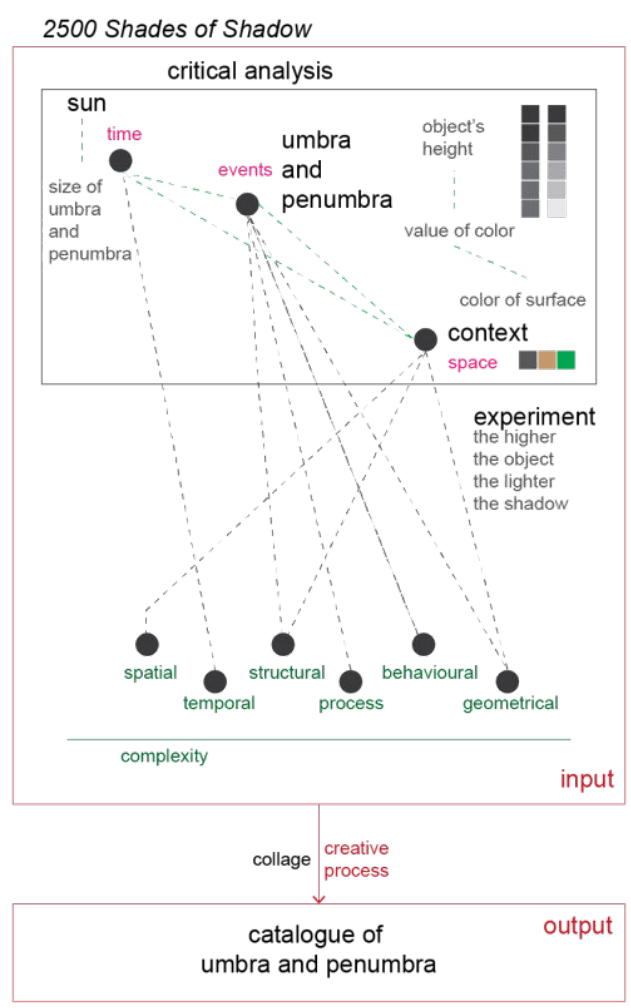

Fig. 7. Mapping 2500 Shades of Shadow in the Complexity of Ecological System. 
Figure 7 shows how 2500 Shades of Shadow has umbra and penumbra as the main 'ecological' event that consists of intra/interrelated elements, exist in particular settings, and has the sun as the source of light that signifies time. When we discuss the system of umbra and penumbra, there are structural, process, behavioural, and geometrical complexity within. Then, settings of which umbra and penumbra exits will have spatial, structural, and geometrical complexity.

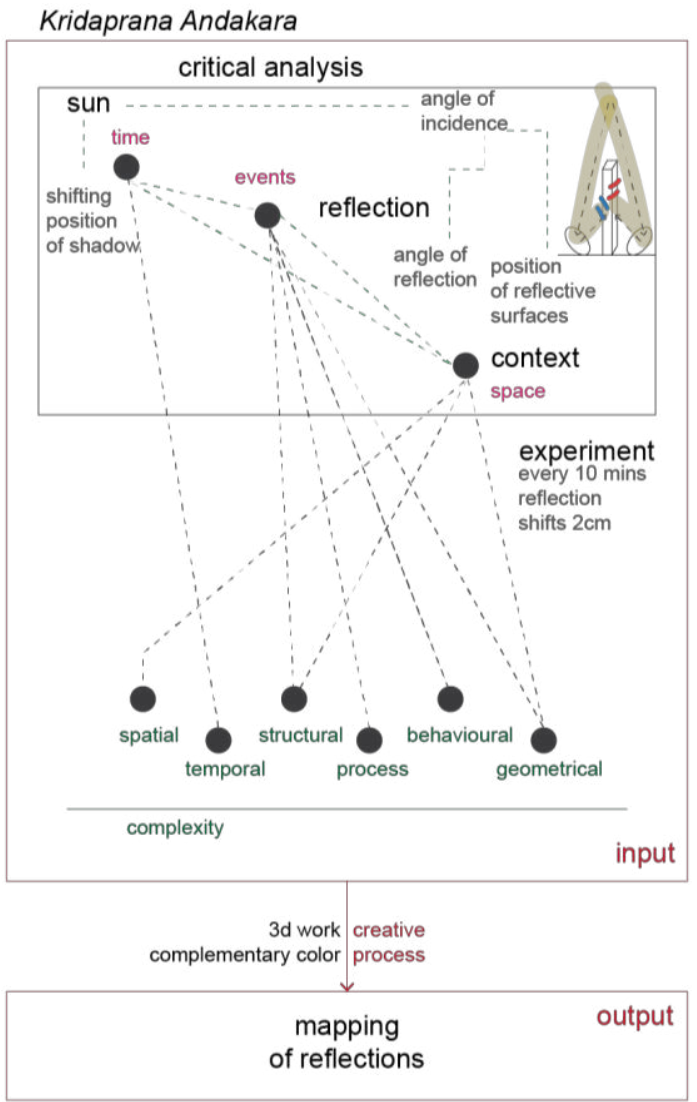

Fig. 8. Mapping Kridaprana Andakara in the Complexity of Ecological System.

The process is also applied in Kridaprana Andakara, shown in Figure 8. This project has an understanding of reflection as the 'ecological' event that has structural, process, behavioural, geometrical complexity within. Elements that are existed, such as the reflective surfaces will have their behavioural and geometrical complexity. Spatial, structural, and geometrical complexity arise in the process of mapping the experiment of shifting position of sunlight's reflections.

As in Distorsi Dalam Waktu, as shown in Figure 9, the main 'ecological' event is the shadow of a man-made object in outdoor settings. Discussion on how this happened has spatial, structural, behavioural, and geometrical complexity. Elements of the event have at least behavioural and geometrical complexity that could relate to spatial and structural complexity too.

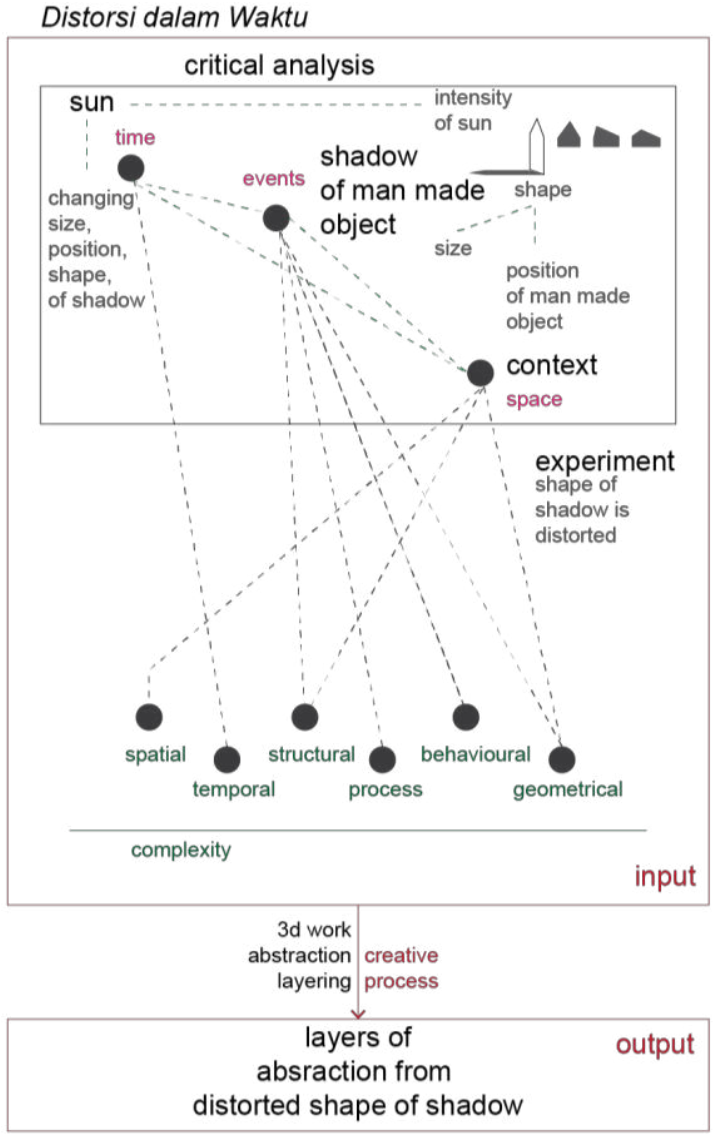

Fig. 9. Mapping Distorsi Dalam Waktu in the Complexity of Ecological System.

The three projects above are under the influence of time because they have the sun as the primary source of light. This comprises temporal complexity in the system that complements the relationships among elements.

\section{Ecology and Dynamicity}

In Landscape of Light and Shadow Project, the students are directed to learn about ecology through a creative process. The idea of ecology that is studied and explored is focusing on how to reveal interrelated system by using 'ecological' analytical tool. It shows how the understanding of ecology could be embedded in the early stage of architectural education and could derive creative works. If we reflect on the discussion, complexity in ecological understanding provides an analytical framework in understanding interrelated system. The analytical framework is formed by the nature of every element in the complexity that always has relation and interaction among one another for the purpose of maintaining a system. In other word in using this ecological understanding, analytical process is not limited to the relation and the interaction between elements, but extended to seeing the result of the relation and the interaction. Various elements and complexities will create diverse combinations of relations and interactions that will lead to different results. Furthermore, any changes of internal and external properties will affect elements and the relations within. 
This fact shows that ecological system is dynamic; it changes and fluctuates in time depending on the condition and the relations that occur.

Goodbun (2012) suggests that, based on Gregory Bateson, the ecology that is required to understand a complex system is the ecology that prioritises flexibility. This statement shows that flexibility, that entails dynamicity, is important in understanding a complex system. This dynamicity in ecological system, arises because of the complexity itself. Several types of complexity that is proposed by Loehle (2004), such as temporal, behavioural, spatial and geometrical complexity, already imply dynamicity within. So, it can be concluded that, beside complexity, dynamicity is also the nature of an ecological system. Dynamicity in ecological system, as an analytical tool, plays a role in allowing different perspectives to emerge, and in relation to architectural education, dynamicity in ecological system is beneficial and aligned with the spirit of creative process.

In the process of the final projects, dynamicity emerges through various experiments that are conducted by the students. The experiments examine specific issues and contain manipulation of elements that are involved within. The experiments also involve independent tools and devices to test the issues. The experiments lead to diverse yet specific findings to understand the ecological events of light and shadow. Concerning the creative process in architectural education, dynamicity and complexity of ecological system are undeniably essential in supporting it as 'ecological' analytical tools in creative process.

\section{Conclusion}

Ecology as a discipline is strongly relevant to architectural education. Ecology is utilised to learn about sustainability through a rather quantitative approach to achieve efficient and environmental friendly problem solving. This paper particularly addresses this issue by presenting an alternative possibility to integrate the idea of ecology in architectural education. The idea of ecology as a study on interrelated systems could be transformed into an analytical tool that could reveal complex systems and issues. Its nature of having complexity and dynamicity makes ecology a complete analytical tool that could lead to a deep understanding through an explorative process. Beside as an analytical tool, the understanding of ecology also reflects spatial understanding. As an event that exists in space and through time, relation and interaction in ecology also leads to the understanding of spatial relation. To think ecologically means to think spatially. This is also one of the potentials of ecology that could be used in architectural education.

In the Department of Architecture Universitas Indonesia, analytical skill and creative thinking are considered essential in the educational process. Since the early stage of the education, we always incorporate analytical skill in the process, aiming for critical thinking. Together with creativity, analytical skill will be an adequate instrument to determine creative design work with a strong analytical background addressing specific issue. Because of this consideration, we, as teacher, get opportunities to explore various teaching methods that will be beneficial for the progress of our architectural education. The Light and Shadow project is one of the example of our exploration in making an integrated exercise based on our proposition and understanding towards ecology, that will give the students opportunity to understand issues in a holistic way and to create creative works based on a through analytical process.

\section{Acknowledgement}

The Works included in this paper are the work of Architecture Students, from the Regular and International program, Universitas Indonesia, class of 2016. The works are part of Landscape of Light and Shadow project as the final project for Basic Design Studio 1 in 2016.

\section{References}

Catalá, A. (2010). Numerical Ecosystems. Architectural Design, 80(6), pp.86-93.

Goodbun, J. (2012). Flexibility and Ecological Planning: Gregory Bateson on Urbanism. Architectural Design, 82(4), pp.52-55.

Goodman, J. (2010). Gregory Bateson's Ecological Aesthetics - an addendum to Urban Political Ecology. Field: a free journal for architecture, 4(1), pp.35-48.

Hartvigsen, G., Kinzig, A. and Peterson, G. (1998). Complex Adaptive Systems: Use and Analysis of Complex Adaptive Systems in Ecosystem Science: Overview of Special Section. Ecosystems, 1(5), pp.427430.

Ingersoll, R. (2012) The Ecology Question and Architecture. In: Cattaneo, E., Ardesio, G., and Andolina, M. (2013) Loaded void: city theory since 1956 : falling modernism and arising landscape urbanism. Santarcangelo di Romagna: Maggioli. pp. 786-802

Loehle, C. (2004). Challenges of ecological complexity. Ecological Complexity, 1(1), pp.3-6.

Newell, J. and Cousins, J. (2014). The boundaries of urban metabolism. Progress in Human Geography, 39(6), pp.702-728.

Proctor, J. and Larson, B. (2005). Ecology, Complexity, and Metaphor. BioScience, [online] 55(12), pp.1065-1068. Available at: http://www.jstor.org/stable/10.1641/00063568(2005)055[1065:ecam]2.0.co;2 [Accessed 18 Sep. 2017].

Sykes, A. (2010). Constructing a new agenda. New York: Princenton Architectural Press 